\title{
A INFORMALIDADE NO MERCADO DE TRABALHO E O IMPACTO DAS INSTITUIÇÕES: UMA ANÁLISE SOB A ÓTICA DA TEORIA DOS JOGOS*
}

\author{
Fernando B. Meneguin ${ }^{\S}$ \\ Maurício S. Bugarin ${ }^{\S}$
}

\begin{abstract}
RESUMO
Este artigo analisa a informalidade no mercado de trabalho, com um jogo dinâmico infinito entre empregador e empregados, no qual a Justiça Trabalhista é representada parametricamente. Duas classes de equilíbrios de Nash perfeitos em subjogos são encontradas. Na primeira classe, a relação informal prevalece durante um determinado tempo, com posterior formalização do trabalhador, sendo que, quanto mais efetiva for a Justiça, mais rapidamente serão registrados os empregados. Na segunda classe, a informalidade se pereniza, associada a uma alta rotatividade no mercado de trabalho. Novamente, quanto mais efetivo o Judiciário, menor a probabilidade de esse último equilíbrio existir.
\end{abstract}

\section{ABSTRACT}

This article presents a game theoretic analysis of informality in the labor market based on an infinite dynamic game between employers and workers in which the Judiciary system enters parametrically. We find two classes of subgame-perfect Nash equilibria. In the first class, the worker first gets an informal contract but he eventually becomes a formal worker. We show that the more effective the Judiciary system, the faster the labor relationship is formalized. In the second class informal labor is maintained, coupled with high work turnover. Again, the more efficient the Judiciary system, the less likely is that equilibrium.

Palavras-chave: teoria dos jogos, mercado de trabalho, instituições.

Keywords: game theory, labor market, institutions.

JEL classification: J63, C72.

* Os autores agradecem a Mirta Bugarin, Marcelo Neri, André Rossi Oliveira, Carlos Alberto Ramos, aos participantes do Annual ALACDE Conference, do XXIX Encontro Brasileiro de Econometria, bem como a dois pareceristas anônimos, por comentários e sugestões que em muito contribuíram para a qualidade deste trabalho. Eventuais erros e/ou omissões permanecem de inteira responsabilidade dos autores.

$\S$ Doutor em Economia. Consultor Legislativo do Senado Federal. Endereço para contato: Senado Federal/Consultoria Legislativa - Anexo II - Bl. B - 2º andar. CEP 70165-900 - Brasília, DF. E-mail: meneguin@senado.gov.br.

a Ph.D. em Economia. Professor Titular do Ibmec São Paulo. Endereço para contato: Ibmec São Paulo, Rua Quatá 300, Vila Olímpia. CEP 04546-042 - São Paulo, SP. E-mail: bugarin@isp.edu.br.

Recebido em agosto de 2007. Aceito para publicação em junho de 2008. 


\section{INTRODUÇÃO}

O funcionamento do mercado de trabalho vem ocupando cada vez mais espaço nas discussões nacionais. São freqüentemente assinaladas importantes imperfeições nesse mercado, como patamares elevados de desemprego, alta taxa de informalidade, a freqüência do litígio nos tribunais trabalhistas, a alta desigualdade de renda e o alcance limitado das leis trabalhistas e das intervenções governamentais para prestar assistência aos trabalhadores.

Neste estudo, especial atenção será dada à informalidade. Justifica nossa escolha a gravidade do assunto, conforme evidencia a seguinte informação: entre 1991 e 2002, conforme dados da Pesquisa Mensal de Emprego (PME) do Instituto Brasileiro de Geografia e Estatística (IBGE), houve um crescimento, nas regiões metropolitanas, das relações informais de trabalho - trabalho assalariado sem carteira e trabalho por conta própria - de quase dez pontos porcentuais na média. Já o estudo em Ribeiro e Bugarin (2003) sugere um crescimento de $26 \%$ no índice da economia submersa no período de agosto de 1994 a julho de 1998.

Assim, o foco deste texto será a qualidade dos postos de trabalho e as relações empregatícias firmadas. Segundo Neri (2000, p. 38), "nenhum segmento contribui mais para a pobreza brasileira do que o setor informal. Cerca de $51,3 \%$ dos pobres brasileiros estão em famílias chefiadas por indivíduos ocupados no segmento informal". O autor critica a direção do debate social brasileiro, que, "ao focar excessivamente o desemprego metropolitano, exclui o pobre. Este não pode se dar ao luxo de ficar buscando emprego, pobre cai na informalidade."

A caracterização do setor informal não é tarefa trivial, conforme se discute em Ramos (2007). ${ }^{1}$ De fato, existem distintas conceituações para o que vem a ser o setor informal. Pela legislação brasileira, trabalhadores registrados são aqueles que possuem a carteira de trabalho assinada, o que garante benefícios como repouso semanal remunerado, contribuição para a seguridade social, direito a requerer seguro-desemprego e a ter uma compensação financeira no caso de demissão sem justa causa, licença gestante e paternidade. Por essa ótica, estariam na informalidade aqueles trabalhadores que não possuem registro, ou seja, aqueles que deveriam possuir carteira de trabalho assinada, mas não a têm. Segundo a Organização Internacional do Trabalho (OIT), ao setor informal são ainda agregadas as pessoas sem remuneração e os autônomos (em que não há uma separação nítida entre a propriedade do empreendimento e a execução de suas atividades). Outra possível definição é considerar informal aquele cidadão não segurado pela Previdência Social. Conforme dados da Pesquisa Nacional por Amostra de Domicílios (PNAD/IBGE), dos 64 milhões de trabalhadores do setor privado em 1999, 62\% não contribuem para a Previdência Social. ${ }^{2}$ Isso se configura num problema tanto social quanto fiscal. No presente trabalho, consideramos trabalhadores informais aqueles que já trabalham em alguma firma, mas não têm suas carteiras de trabalho registradas.

1 Veja também as discussões cuidadosas sobre diferentes conceitos de economia informal em Cacciamali (1991) e Ribeiro e Bugarin (2003).

2 Informação constante da publicação do Ministério da Previdência Social: Conjuntura Social, v. 14, n. 1, p. 65, maioago 2003 . 
A literatura sobre informalidade no mercado de trabalho brasileiro consiste principalmente em artigos que discutem as políticas públicas de combate ao problema e trabalhos empíricos com análises econométricas.

Ramos e Britto (2004, p. 8) argumentam que o crescimento da informalidade "representa um foco de preocupação em relação à perda de arrecadação tributária. Uma corrente de estudiosos do mercado de trabalho advoga que esse fenômeno é propiciado pelos elevados encargos trabalhistas impostos pela relação formal de trabalho, que faria com que o custo do fator trabalho dobrasse, segundo alguns cálculos, em relação ao salário efetivamente recebido pelo trabalhador. $A$ discussão em torno da flexibilização da legislação trabalhista - nessa perspectiva - poderia oferecer algumas soluções que amenizassem a gravidade do problema, mas o debate a respeito é intenso e não há consenso estabelecido."

Camargo (1996, p. 11) foca o papel dos incentivos no comportamento do mercado de trabalho associado ao marco institucional. Segundo o autor, "a possibilidade de negociar os direitos individuais inscritos na CLT e na Constituição através da Justiça do Trabalho cria um incentivo adicional para que os empresários não respeitem a legislação enquanto o trabalhador está empregado, ao mesmo tempo que induz o trabalhador a forçar sua demissão para receber pelo menos parte desses direitos, através da Justiça, quando demitido. O resultado são elevadas taxas de rotatividade da mão-de-obra e baixo nível de cumprimento da legislação trabalhista". Em suas conclusões, o autor ainda completa que, "além de criar incentivos à baixa qualificação, as instituições também criam incentivos à informalidade. Esses incentivos decorrem do elevado nível de impostos sobre os salários e da forma pela qual está desenhado o programa de seguro-desemprego."

A diferença de remuneração percebida pelos empregados do setor formal em comparação aos do setor informal é assunto recorrentemente estudado. Conforme o Anexo Estatístico da publicação do IPEA, Mercado de Trabalho - Conjuntura e Análise, n. 24, o diferencial de rendimentos efetivamente recebidos pelos empregados do setor privado com e sem carteira assinada, nas regiões metropolitanas pesquisadas, entre janeiro e maio de 2004, foi em média 62,3\%, ou seja, os trabalhadores com contrato de trabalho formalizado perceberam uma remuneração $62,3 \%$ maior quando comparados aos integrantes do setor informal.

Menezes-Filho, Mendes e Almeida (2001) utilizam um método econométrico de crosssection repetidas e concluem que o diferencial de salários observados entre formais e informais decorre da melhor qualidade da força de trabalho empregada no setor formal.

Soares (2004a) documenta, com base em dados da Pesquisa Nacional por Amostra de Domicílios (PNAD), referentes ao período de 1981 a 1999, o aumento na proporção de empregados sem registro em carteira e a redução no diferencial de salários entre trabalhadores registrados (com carteira) e sem registro (sem carteira). O porquê e a maneira como ocorreram essas alterações no mercado de trabalho são, segundo o autor, questões abertas ao debate.

Já em Soares (2004b), demonstra-se a existência de uma fila por trabalhos formais no mercado de trabalho brasileiro. Quando os trabalhadores informais foram solicitados a responder 
se trocariam sua situação por um emprego formal, $70 \%$ responderam positivamente. Os que mais apresentam dificuldades para conseguir um emprego formal são os negros, as mulheres, os analfabetos, os jovens sem experiência e os que, no último trabalho, estavam em situação informal. $^{3}$

Ulyssea (2005a) sistematiza os principais estudos sobre informalidade no Brasil, enfatizando o diferencial de salários entre trabalhadores formais e informais, a segmentação no mercado de trabalho e os efeitos das instituições sobre o setor informal.

Ramos e Ferreira (2005) examinam a evolução da informalidade no Brasil a partir de 1991. Utilizam-se das bases de dados da PNAD e da PME, concluindo que a informalidade cresceu muito nas regiões metropolitanas, embora tenha diminuído no restante do País. Em termos setoriais, tanto a indústria quanto o setor de serviços contribuíram para o aumento da informalidade, apesar de o movimento acontecer por razões distintas: "no caso do setor de serviços foi seu crescimento, enquanto na indústria foi sua crescente informalização.”

Nessa breve revisão dos trabalhos existentes, percebe-se como a proliferação das práticas informais despertou interesse entre especialistas e sociedade em geral. Não é para menos, pois o crescimento do chamado setor informal, normalmente associado à precarização da qualidade do trabalho, à fragilização da inserção no mercado e à banalização dos vínculos empregatícios, foi uma das tônicas do período a partir dos anos 1990.

Na literatura internacional, destacam-se Rauch (1991) e Acemoglu (2001). O primeiro faz a definição, em seu modelo, de formal ou informal, conforme a firma cumpra ou não a legislação do salário mínimo e, por meio de uma análise de estática comparativa, conclui que o aumento do salário mínimo acarreta uma elevação no diferencial de salários e na disparidade de tamanho entre os setores formal e informal.

Acemoglu (2001) elabora um modelo de matching com dois setores, em que a taxa de desemprego, o diferencial de salários entre os dois setores e a composição setorial do emprego são variáveis endógenas. O objetivo é analisar os impactos das instituições do mercado de trabalho sobre seus indicadores e resultados como a produtividade média e o nível de emprego da economia. Uma das principais conclusões do estudo consiste no fato de o seguro-desemprego gerar efeitos positivos na composição do emprego e na produtividade média. Cabe ainda citar Ulyssea (2005b) que constrói um modelo, a partir de Acemoglu (2001), para o caso brasileiro. Utiliza a tecnologia de matching com dois setores - formal e informal - que considera algumas das variáveis relacionadas ao mercado de trabalho como custos de admissão e demissão, tributos sobre a folha de salários, seguro-desemprego, entre outros.

Considerando todo o exposto, que bem reflete a relevância do tema, o objetivo do presente texto é fazer uma análise com uma abordagem diferenciada das relações informais de trabalho, por meio da Teoria dos Jogos. Procura-se entender melhor o comportamento dos agentes envolvidos - trabalhadores e patrões - e o efeito das instituições no funcionamento do mercado

3 Veja também estudo sobre diferença salarial entre homens e mulheres no Brasil em Madalozzo e Martins (2007). 
laboral. Mais especificamente, será enfatizada a interação entre a informalidade e a Justiça Trabalhista.

Para realizar a análise proposta, é construído um jogo dinâmico e infinito, com dois jogadores: trabalhadores e patrões. A Justiça Trabalhista é representada no modelo por um parâmetro que aumenta ou diminui o custo dos empregadores em termos de encargos trabalhistas quando há dissídio e esta é acionada. Pretende-se explicar, com os equilíbrios de Nash do jogo, como é determinado o tempo de informalidade a que o trabalhador é submetido, bem como uma possível causa para a alta rotatividade da mão-de-obra. A principal mensagem dos equilíbrios encontrados é que quanto mais ágil for a Justiça no julgamento de ações trabalhistas, menor será o tempo em que um trabalhador será mantido em situação informal antes de ser contratado formalmente por uma empresa. A segunda importante mensagem diz que, quanto mais lenta for a Justiça no julgamento de ações trabalhistas, maior será a rotatividade dos trabalhadores em empregos que não são formalizados. Por outro lado, quanto mais ágil for a Justiça Trabalhista, menor será a probabilidade de existir um equilíbrio em que os empregados nunca têm suas carteiras assinadas.

Reforçando a argumentação que será usada neste artigo, pode-se citar Perry et al. (2007, p. 2), em que os autores adotam como uma das razões da informalidade o fato de que cada agente procura o melhor para si, mesmo que isso signifique o descumprimento das normas trabalhistas. Segundo o texto, "muitos trabalhadores, empresas e famílias escolhem o seu melhor nível de envolvimento com as normas e instituições públicas, dependendo de sua avaliação dos benefícios líquidos associados à informalidade e do esforço e capacidade do Estado para fazer cumprir as leis. Ou seja, eles fazem análises implícitas do custo-benefício de ultrapassar a importante margem para a formalidade e freqüentemente desejam não fazê-lo."

Na mesma direção, Ramos (2007, p. 32), ao discutir os atrativos da informalidade, afirma que "o ônus associado aos encargos sociais do trabalho tende a produzir um incentivo à sua sonegação como forma de redução de custos e aumento, ou manutenção, de margens de lucros, particularmente em tempos de retração da atividade econômica."

O tema aqui introduzido encontra-se dividido como se segue. A próxima seção aborda alguns aspectos que envolvem os entes associados ao mercado de trabalho, principalmente os tribunais trabalhistas no Brasil. A Seção 3 traz a modelagem formal propriamente dita. A propriedade do desvio em um único estágio é descrita na Seção 4. A quinta seção analisa um equilíbrio em que a formalização do empregado é adiada e a Seção 6 discute outro equilíbrio em que nunca ocorre o registro do trabalhador. Finalmente, têm-se as considerações finais e conclusões. 


\section{ASPECTOS DO MERCADO DE TRABALHO BRASILEIRO}

O mercado de trabalho tem a função de fazer a ponte entre a procura por mão-de-obra e a oferta de trabalho. É de suma importância, portanto, que esse vínculo esteja funcionando adequadamente. A ausência de um bom funcionamento no mercado de trabalho pode fazer com que o crescimento econômico não gere empregos ou, ainda, que os investimentos em educação e novas tecnologias não signifiquem ganhos de produtividade e melhores salários.

As engrenagens do mercado de trabalho podem ser afetadas de três formas: a) pelas instituições, como os tribunais trabalhistas; b) pelas regulamentações, a exemplo das normas que regem a demissão de trabalhadores, e c) pelas intervenções, como os programas de segurodesemprego.

Provavelmente, as instituições que mais influenciam o mercado de trabalho são os tribunais trabalhistas, de maneira que é importante detalhar seu funcionamento.

Segundo o IPEA e o Banco Mundial, ${ }^{4}$ a cada ano são ajuizados, no Brasil, 2 milhões de ações judiciais pelos trabalhadores contra seus empregadores atuais ou passados. Depois de iniciada a ação judicial, o caso vai para conciliação. Se não houver acordo, a matéria é encaminhada ao juiz. A duração média para se ter uma decisão é de 31 meses, sendo que pode haver apelação da sentença por duas vezes.

Este mesmo relatório informa que o procedimento comum dos tribunais trabalhistas é ratear o valor da ação: os trabalhadores recebem aproximadamente $40 \%$ do valor disputado, o que faz com que os assalariados tenham incentivos a litigar na justiça com mais freqüência e inflacionar suas demandas. Em contrapartida, os empregadores se sentem estimulados a não pagar todos os direitos acumulados dos trabalhadores na rescisão e a aguardar até que sejam obrigados a fazê-lo judicialmente.

Os benefícios para o trabalhador, decorrentes da rescisão, são basicamente três: o empregado ganha permissão para sacar o saldo do Fundo de Garantia do Tempo de Serviço - FGTS -; recebe multa indenizatória por rescisão sem justa causa, que consiste no pagamento, pelo empregador, de 40\% do saldo do FGTS (além disso, o empregador paga 10\% ao governo), e tem aviso prévio com um mês de antecedência ou um mês de salário.

O relatório do IPEA e do Banco Mundial (2002, p. 26) resume bem os efeitos da Justiça Trabalhista no seguinte parágrafo:

Dada a alta incidência de causas trabalhistas, não surpreende que a justiça do trabalho influencie significativamente os produtos do mercado de trabalho. Os tribunais impõem custos diretos e indiretos aos usuários. Os custos diretos dos litígios mais freqüentes são as taxas pagáveis ao Estado e aos advogados, que são suportados pelas empresas. Estes custos não são desprezíveis. Todavia, os custos indiretos devidos à mudança de comportamento

4 Banco Mundial; IPEA (2002). 
são muito maiores e recaem sobre os empregados e os empregadores. O litígio freqüente implica que os custos de mão-de-obra em termos de pagamento futuro de multas e honorários advocatícios são incertos para o empregador no tempo do emprego. O preço real da mão-de-obra só será conhecido cinco anos depois da rescisão do contrato - após o que o sistema judiciário não aceita mais denúncias. Frente a essa incerteza, os empregadores se tornam cautelosos na contratação de novos trabalhadores, aumentando o cuidado na triagem e, dessa forma, aumentando igualmente seus custos de contratação. Embora não existam provas sistemáticas, é provável que isto tenha reduzido o emprego.

Outra informação ressalta os problemas enfrentados pela Justiça Trabalhista, o que pode estar influenciando negativamente o mercado formal. Trata-se da carga de trabalho por magistrado de $2^{\text {a }}$ instância nos Tribunais Regionais do Trabalho - TRTs. Conforme Relatório Geral da Justiça do Trabalho de 2006, a média nacional da carga, no ano de referência, foi de 1842 processos, enquanto, em 2005 e 2004, a carga foi estimada em 1790 e 1065 processos, respectivamente. Ou seja, observa-se um aumento do estoque nos TRTs no decorrer do tempo.

O modelo apresentado na seção seguinte tentará representar o funcionamento do mercado de trabalho e como a atuação dos tribunais trabalhistas interfere na expectativa e no comportamento dos agentes, favorecendo a informalidade, que, conforme o gráfico a seguir, apresenta uma tendência crescente.

\section{Gráfico 1 - Grau de informalidade (em \%)}

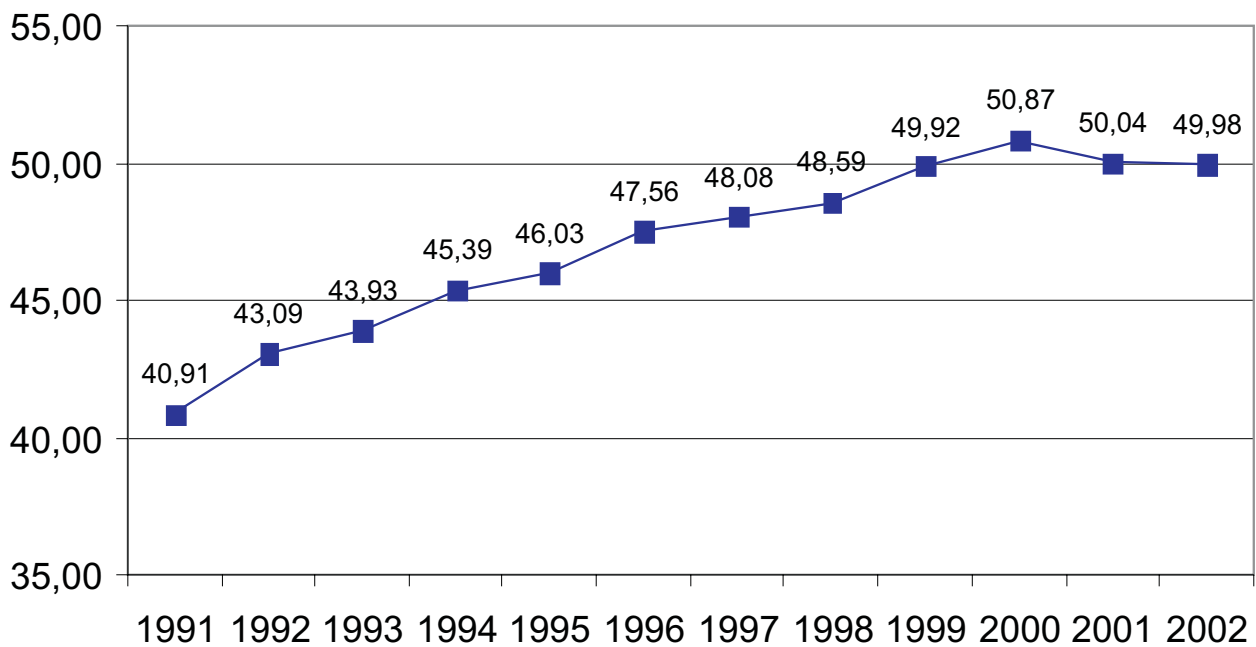

Fonte: PME/IBGE.

Notas: Refere-se à informalidade no mercado de trabalho metropolitano. Os valores correspondem às médias aritméticas anuais.

Cabe ainda mencionar outro grave aspecto do mercado laboral brasileiro: a alta rotatividade. Apesar de a rotatividade ser inerente a qualquer mercado de trabalho, ela gera custos, como os encargos decorrentes de uma demissão. Se esses custos são altos, os empregadores, na

5 A carga de trabalho corresponde ao estoque de processos acumulados. 
expectativa de ter sua força de trabalho renovada constantemente, têm menos incentivos para investir no treinamento individual dos trabalhadores.

Corseuil et al. (2002, p. 39), ao analisar essa distorção, conclui que a "rotatividade brasileira é de fato elevada, mas heterogênea. Setores como comércio e serviços apresentam alta taxa de realocação de emprego e são responsáveis por grande parte da rotatividade agregada. Firmas pequenas revelaram ser as maiores responsáveis tanto pela criação de emprego quanto pela rotatividade total." Em compensação, no setor secundário, a rotatividade é mais baixa. O modelo a ser apresentado sugere que a Justiça Trabalhista também interfere na rotatividade do mercado de trabalho.

De posse dessas informações e evidências, passa-se à modelagem formal com o intuito de estudar esses pontos sob o prisma do comportamento estratégico.

\section{MODELO TEÓRICO}

Com o intuito de entender as relações entre os agentes no mercado de trabalho, propõe-se um jogo dinâmico e infinito, de informação completa. Cabe ressaltar que algumas hipóteses nesse modelo se distanciam da realidade do mercado de trabalho brasileiro, sendo usadas aqui tendo em vista possibilitar a análise de um mercado extremamente complexo, na esperança de trazer à tona reflexões importantes que possam ser transformadas em políticas públicas relevantes.

Na modelagem, o trabalhador (T) inicialmente terá duas opções: ou ele escolhe ser autônomo (a) e, nessa situação, aufere a renda $\gamma \geq 0$ ou ele prefere ser empregado (emp) na empresa (E).

Se ele optar por ser assalariado, tem-se então a decisão da empresa (E). Ela poderá registrar o empregado (reg), assinando a carteira de trabalho, e pagar, além da remuneração $(r)$, todos os encargos trabalhistas (e) que correspondem aos benefícios (b) devidos ao trabalhador, mais as contribuições patronais $(p)$ que a empresa recolhe ao governo: $e=b+p$. Ou, então, a firma poderá decidir não registrar o empregado (nreg) e mantê-lo na informalidade, pagando apenas a remuneração $r$.

Caso a empresa registre o empregado, o emprego se torna formal e assim persiste, sem que exista qualquer oportunidade de comportamento estratégico futuro. Observe que o presente modelo, estando centrado na decisão de formalizar ou não o vínculo empregatício pela empresa, omite qualquer análise a respeito de incentivos internos à dedicação do empregado. Em particular, não há consideração a respeito de incentivo adverso (moral hazard) nem de seleção adversa, uma vez assinada a carteira de trabalho.

Por outro lado, caso o empregado fique na informalidade, ele pode se acomodar, recebendo apenas sua remuneração $r$, ou então denunciar a empresa à Justiça Trabalhista. Se assim fizer, 
receberá sua remuneração mais um porcentual $\alpha$ dos benefícios trabalhistas a que teria direito $(0<\alpha<1)$. O parâmetro $\alpha$ representa as instituições trabalhistas: quanto maior for $\alpha$, maior o benefício para o trabalhador em acionar na Justiça o empregador.

No presente modelo, adota-se por simplicidade que o empregado denuncia a empresa e é demitido simultaneamente. Mais ainda, se for demitido, permanecerá autônomo, recebendo a partir de então o salário $\gamma$. Segundo matéria publicada na Folha de São Paulo, em 05/05/2003, pelo menos $80 \%$ dos processos que chegam às mãos dos juízes trabalhistas são movidos por quem está sem emprego, conforme levantamento do Tribunal Superior do Trabalho - TST. No caso dos outros 20\%, boa parte das ações é contra ex-patrões. O Ministro Francisco Fausto, presidente do TST, afirma que "quem está empregado não procura os seus direitos na Justiça porque as relações de emprego estão cada vez mais precárias.” O presidente da Associação Nacional dos Magistrados da Justiça do Trabalho - ANAMATRA - acrescenta que "o trabalhador teme ir à Justiça porque existe no país uma cultura de represália aos que buscam seus direitos", fazendo referência à existência de uma lista negra que consiste em um documento que circula entre as empresas para identificar o trabalhador que recorreu à Justiça.

Se o empregado for demitido, a empresa terá ainda a opção de contratar novo trabalhador no lugar vago, desde que haja demanda de trabalho. Por simplicidade, qualquer trabalhador gera a mesma receita $R$ para a firma e o salário $r$ é dado pelo mercado. Por hipótese $R>r+$ $e$, de forma que a firma sempre tem incentivo a manter o trabalhador, independentemente do regime de contratação ser formal ou informal. Portanto, a decisão da firma se restringe a manter o trabalhador informal, ao custo mínimo de seu salário $r$, ou formalizá-lo, adicionando ao custo os encargos $e=b+p$. Já o trabalhador, além de decidir se torna-se autônomo ou busca emprego, caso procure emprego e seja contratado informalmente, decide se denuncia na Justiça a firma, e é demitido, ou se cala diante da informalidade, mantendo seu emprego.

A Figura 1 apresenta o jogo em seu estágio inicial em maiores detalhes. $\mathrm{O}$ trabalhador (T) começa escolhendo entre ser autônomo, (a), ou procurar emprego, (emp). Se decidir ser autônomo, fará jus à receita $\gamma$. O payoff da firma com esse trabalhador é naturalmente 0 . Caso decida procurar emprego, a firma o contrata e decide se assina carteira de trabalho (reg) ou o mantém na informalidade (nreg). Caso registre o emprego, o trabalhador permanece empregado nos próximos períodos, recebendo sempre o salário $r+b$, encerrando-se também, neste caso, qualquer interação estratégica. O payoff da firma com esse trabalhador é $R-(r+e)$. Caso a firma mantenha o trabalhador na informalidade, este deve decidir se aceita a situação de informalidade (aco), recebendo então a renda $r$ ou se, ao final do período, aciona a firma na Justiça, garantindo assim o salário $r+\alpha b, \alpha \in[0,1]$. Se o trabalhador se acomodar, a firma recebe o payoff $R-r$ e o trabalhador continua trabalhando. Caso o trabalhador acione a firma na Justiça, ele recebe $r+\alpha b$ e perde seu emprego, tornando-se autônomo nos próximos períodos. Já a firma tem por payoff $R-[r+\alpha(b+p)]$. Caso o trabalhador decida manter-se autônomo nesse estágio inicial, um novo "estágio inicial” (do) se repete no estágio seguinte.

6 Fernandes, F.; Rolli, C. (2003). 
Figura 1 - Estágio inicial do jogo entre um trabalhador e uma firma

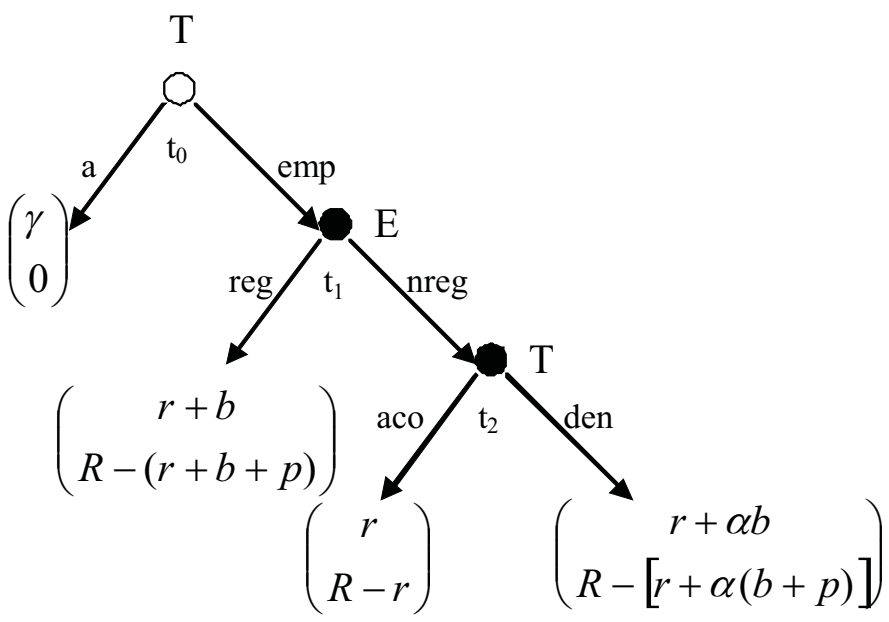

A Figura 2 representa o jogo em seu estágio $n>1$, na situação em que a empresa ainda não formalizou o contrato com o trabalhador. Trata-se da única situação em que existe comportamento estratégico na continuação do jogo descrito no estágio inicial. Observe que, quando o empregado decide acionar judicialmente a firma, ele recebe $r+\alpha n b$, ou seja, além do salário $r$, recebe a parcela $\alpha$ do total dos benefícios não pagos nos $n$ estágios: $n b$. Já a firma tem por payoff $R-[r+\alpha n(b+p)]$. Portanto, quanto mais tempo passar na informalidade, maior é o custo de oportunidade para o trabalhador de permanecer mais um período na informalidade.

Figura 2 - Estágio $n>1$ do jogo entre um trabalhador sem carteira assinada e uma firma

$$
\left(R-(r+b+p){ }_{\left(\begin{array}{c}
r \\
r+b \\
R-r
\end{array}\right)}\left(\begin{array}{c}
r+\alpha n b \\
r-[r+\alpha n(b+p)]
\end{array}\right)\right.
$$

Para se computar o retorno total para cada agente associado e um perfil de estratégias no jogo infinito desconta-se os payoffs do segundo estágio pelo fator de desconto intertemporal $\delta$ $(0<\delta<1)$, do terceiro estágio por $\delta^{2}$, do $n$-ésimo estágio por $\delta^{n-1}$, como de praxe.

Além disso, será adotada também a hipótese de que $r+b>\gamma$, ou seja, o retorno total do trabalhador com carteira assinada é maior que o retorno do trabalhador autônomo. Essa hipóte-

7 Por simplicidade, não consideramos a correção monetária da quantia não paga no passado. Esta simplificação não implica qualquer perda de generalidade nos resultados a seguir. 
se é confirmada em Soares (2004b) e pode ainda ser verificada pelos dados da Pesquisa Mensal de Emprego do Instituto Brasileiro de Geografia e Estatística, IBGE, ${ }^{8}$ tendo por conseqüência a conclusão de que, se o trabalhador tiver a opção, preferirá ser empregado com certeira assinada a ser autônomo.

\section{A PROPRIEDADE DO DESVIO EM UM ÚNICO ESTÁGIO}

Para encontrar os equilíbrios de Nash perfeitos em subjogos, será utilizada a propriedade denominada One-Stage-Deviation, ${ }^{9}$ ou desvio em um único estágio. Essa propriedade garante que um perfil de estratégias é perfeito em subjogos se não for possível, para nenhum jogador, desviar unilateralmente de sua estratégia de equilíbrio em um único estágio do jogo e se beneficiar com esse desvio. Em outras palavras, a propriedade permite que se analise o desvio em um único estágio e se conclua pela perfeição em subjogos.

Mais formalmente, por esse princípio, para saber se uma estratégia $s_{i}$, do jogador $i$, é parte de um equilíbrio perfeito em subjogos $\left(s_{i}, s_{-i}\right)$, basta provas de que não existe um histórico $h^{t}$ (definido como a seqüência de ações escolhidas pelos jogadores nos períodos anteriores a $t$ ) em que o jogador $i$ pode obter algum ganho desviando de $s_{i}$ exclusivamente em $t$ e, após esse desvio, retornando a $s_{i}$, dado que os demais jogadores seguem as estratégias $s_{-i}$.

No entanto, para que essa propriedade valha, o jogo deve ter a qualidade de ser "contínuo no infinito". Seja $h$ uma história infinita qualquer, definida como uma seqüência de ações tomadas pelos jogadores ao longo do jogo, e seja $h^{t}$ uma restrição de $h$ para os primeiros $t$ períodos; então um jogo é dito contínuo no infinito se, para cada jogador $i$, a função de utilidade $u_{i}$ satisfaz:

$$
\sup _{h, \tilde{h} \text { s.a. } h^{t}=\tilde{h}^{t}}\left|u_{i}(h)-u_{i}(\tilde{h})\right| \rightarrow 0 \text {, quando } t \rightarrow \infty
$$

Na prática, essa condição diz que os eventos em um futuro distante têm pouca importância. No presente jogo, os payoffs de cada jogador, em todos os estágios, são uniformemente limitados. Como os payoffs no jogo inteiro são descontados a cada período pelo fator de desconto intertemporal $\delta$, segue imediatamente que nosso jogo é contínuo no infinito. Trata-se da observação logo após a Definição 5.1 em Fudenberg e Tirole (1991). Portanto, vale a propriedade de desvio em um estágio para nosso jogo. Na próxima seção, fica clara a utilidade dessa propriedade na solução do modelo desenvolvido.

8 Site http://www.ibge.gov.br/home/estatistica/indicadores/trabalhoerendimento/pme_nova/default.shtm, acessado em 20/3/2008.

9 Fudenberg e Tirole (1991). Teorema 5.2 da subseção 5.2. 


\section{EQUILÍBRIO COM REGISTRO ADIADO}

Nesta seção verificamos se existe um equilíbrio perfeito em subjogos, em que a firma inicialmente contrata o empregado sem registrar sua carteira, mas, após um número $n$ de períodos, formaliza o vínculo empregatício. O perfil de estratégias correspondente é o seguinte: para o trabalhador, busca emprego no estágio inicial (emp) e aceita trabalhar sem registro (aco) até o $n$-ésimo estágio do jogo. Caso não tenha sua carteira assinada até esse estágio, então aciona judicialmente a firma (den). Para a firma, contrata o trabalhador sem assinar sua carteira (nreg) no estágio inicial e o mantém na informalidade até o $n$-ésimo estágio do jogo, quando então assina sua carteira (reg).

\subsection{Análise para a empresa}

Primeiramente, serão analisados os incentivos ao desvio unilateral em um único período do empregador com relação à estratégia anteriormente descrita. Em qualquer estágio em que a firma venha a tomar uma decisão, existe um trabalhador interessado em trabalhar para a firma, independentemente da situação se encontrar dentro ou fora do caminho de equilíbrio.

Caso a firma decida assinar a carteira do trabalhador antes de esse trabalhador concluir $n$ estágios de trabalho, estará arcando com um custo adicional de $e=b+p$, sem nenhum ganho adicional. Portanto, antecipar a formalização do trabalhador apenas reduzirá seu lucro.

Considere agora a possibilidade de a firma não assinar a carteira do trabalhador após $n$ estágios de trabalho. Então o trabalhador denunciará na Justiça a firma, concluindo seu vínculo empregatício, o que representará um custo adicional de $\alpha$ ne nesse estágio para a firma. Além disso, pela propriedade de desvio em um único estágio, a firma contratará outro trabalhador sem carteira assinada no próximo estágio, mas assinará a carteira desse novo trabalhador $n$ estágios depois. Portanto, o ganho líquido para a firma em não assinar a carteira do trabalhador, desviando do perfil considerado, é dado por:

$$
\Delta \pi=e+\delta e+\cdots+\delta^{n-1} e-n \alpha e=\left[\frac{1-\delta^{n}}{1-\delta}-n \alpha\right] e
$$

Os primeiros termos positivos da expressão acima correspondem à economia que a firma fará não pagando os benefícios hoje e adiando por mais $n-1$ períodos a assinatura da carteira (ao contratar o outro empregado). Já o último termo corresponde ao custo atual de ter que pagar o porcentual $\alpha$ dos benefícios acumulados.

A firma não terá interesse em desviar se $\Delta \pi \leq 0$, o que equivale a:

$$
n \geq \frac{1}{\alpha} \frac{1-\delta^{n}}{1-\delta}
$$


Essa última condição deve ser satisfeita para que a empresa tenha incentivo a registrar o trabalhador a partir do período $n$. Note-se que sempre há um valor de $n$ que satisfaz a condição (3), pois, tomando-se os limites, o lado direito tende a $[\alpha(1-\delta)]^{-1}$ enquanto o lado esquerdo tende ao infinito.

\section{Simulação}

De posse dessa expressão, podem-se fazer algumas simulações. Considere-se hipoteticamente um fator de desconto $\delta=0,98$, compatível com uma taxa de juros de $2 \%$ por período. Conforme mencionado na segunda seção, os trabalhadores recebem na Justiça algo em torno de $40 \%$ do valor litigado, ${ }^{10}$ ou seja, $\alpha=0,4$. No entanto, a intenção é variar o valor de $\alpha$ e ver qual intuição nos fornece essa prática. O resultado encontra-se na Tabela 1.

Tabela 1 - Valores de $n(\alpha)$ a partir dos quais a empresa tem incentivo a registrar o empregado

\begin{tabular}{c|c}
\hline$\alpha$ & $n(\alpha)$ \\
\hline 0,3 & 161 \\
0,4 & 112 \\
0,5 & 81 \\
0,6 & 57 \\
0,7 & 39 \\
0,8 & 25 \\
0,9 & 12 \\
\hline
\end{tabular}

Esta tabela mostra que, quanto mais eficiente o quadro institucional ( $\alpha$ maior), ou seja, quanto mais a Justiça Trabalhista obrigar os empregadores a pagarem a integralidade dos benefícios devidos, mais rapidamente o empregador estará disposto a registrar o empregado.

Uma forma alternativa de se entender o coeficiente referente ao quadro institucional, $\alpha$, é interpretá-lo como o tempo necessário para a conclusão do processo, uma vez que um $\alpha$ elevado pode representar maior celeridade nas decisões judiciais, o que aumenta o valor presente do benefício devido ao trabalhador. Nesse caso, quanto maior for $\alpha$, menor será o tempo de espera caso o trabalhador acione a Justiça, portanto, o empregador terá que pagar mais rapidamente sua dívida com o empregado caso este a acione na Justiça, o que aumentará o incentivo para que a firma antecipe a assinatura de sua carteira de trabalho.

Para que a condição (3) da empresa seja um equilíbrio, deve haver um período $n$ que satisfaça essa condição, tal que o trabalhador não esteja disposto a denunciar seu contrato de trabalho antes disso. Resta, então, analisar os incentivos do trabalhador.

10 Banco Mundial; IPEA (2002) 


\subsection{Análise para o empregado}

Analisemos inicialmente se o trabalhador tem incentivo a não buscar emprego, permanecendo autônomo. Pela propriedade de desvio em um único estágio, basta considerar a situação em que o trabalhador permanece autônomo um estágio, mas busca emprego no estágio seguinte, trabalha $n$ estágios sem carteira, tendo então seu emprego formalizado. O benefício líquido do desvio é dado por:

$$
\Delta u=\gamma+\delta\left[r+\delta r+\cdots+\delta^{n-1} r+\delta^{n} \frac{1}{1-\delta}(r+b)\right]-\left[r+\delta r+\cdots+\delta^{n-1} r+\delta^{n} \frac{1}{1-\delta}(r+b)\right]
$$

Os primeiros dois termos positivos da expressão acima correspondem à utilidade quando o trabalhador primeiro mantém-se autônomo por um estágio, buscando emprego em seguida. O último termo, precedido do sinal negativo, reflete a utilidade do trabalhador quando ele segue a estratégia de equilíbrio. A expressão acima pode ser reescrita na forma abaixo.

$$
\Delta u=\gamma-(1-\delta)\left[\frac{1-\delta^{n}}{1-\delta} r+\delta^{n} \frac{1}{1-\delta}(r+b)\right]=\gamma-\left(r+\delta^{n} b\right)
$$

O trabalhador não terá interesse nesse desvio se $\Delta u \leq 0$, o que equivale à condição abaixo.

$$
r+\delta^{n} b \geq \gamma
$$

Por hipótese, baseada em evidência empírica, temos que $r+b>\gamma$. Portanto, a condição estará satisfeita se $\delta$ for suficientemente próximo de 1 e $n$ não for muito elevado, ou seja, a espera para ter sua carteira assinada não for muito grande. Observe que, se $\gamma \leq r$, então o trabalhador não terá interesse a permanecer autônomo qualquer que seja o valor de $n$.

Analisemos agora se o trabalhador, tendo aceitado trabalhar para a firma sem carteira assinada, tem incentivo a desviar em um único estágio da estratégia de equilíbrio, denunciando a firma antes de ter sua carteira assinada. Suponha que o trabalhador desvie do equilíbrio, denunciando a firma no estágio $k<n$. Então, seu benefício líquido é:

$$
\Delta u=\left[r+\delta r+\cdots+\delta^{k-1}(r+k \alpha b)+\delta^{k} \frac{1}{1-\delta} \gamma\right]-\left[r+\delta r+\cdots+\delta^{n-1} r+\delta^{n} \frac{1}{1-\delta}(r+b)\right]
$$

O primeiro termo positivo da expressão acima corresponde à utilidade quando o trabalhador denuncia a firma no estágio $k$, sendo em seguida demitido e permanecendo a partir de então na informalidade. O último termo, precedido do sinal negativo, reflete a utilidade do trabalhador quando ele segue a estratégia de equilíbrio. A expressão acima pode ser reescrita na forma abaixo.

$$
\frac{1}{\delta^{k-1}} \Delta u=k \alpha b-\frac{\delta}{1-\delta}\left[r+\delta^{n-k-1} b-\gamma\right]
$$


Portanto, o trabalhador não terá incentivo a denunciar a firma se for válida a desigualdade a seguir:

$$
\forall k<n, \quad k \leq \frac{1}{\alpha b} \frac{\delta}{1-\delta}\left[r+\delta^{n-k-1} b-\gamma\right]
$$

Observe que, como as funções dos dois lados da igualdade acima são crescentes em $k$, não se pode determinar a priori para que valores de $n$ essa condição será satisfeita. Ademais, o termo à direita é limitado superiormente por $\frac{1}{\alpha b} \frac{\delta}{1-\delta}[r+b-\gamma]$, enquanto o termo à esquerda cresce sem limites (com $n$ e conseqüentemente) com $k$; portanto, se $n$ for muito grande, o trabalhador denunciará a firma com certeza antes ter seu contrato efetivado. No entanto, como $r+b>\gamma$ e como $\frac{\delta}{1-\delta}$ é muito grande, se $n$ não for demasiadamente elevado, é possível satisfazer a condição.

\section{Simulação}

De fato, uma vez conhecidos os parâmetros relevantes, pode-se calcular esses valores de forma bastante direta. A Tabela 2 apresenta os valores máximos de $n$ para os quais o trabalhador não tem incentivo a desviar do equilíbrio, para as configurações dos parâmetros discutidas a seguir. $\mathrm{O}$ fator de desconto continua sendo $\delta=0,98$ e $\alpha$ continuará assumindo seis valores de 0,3 a 0,9 . Neri (2000) estima que os custos trabalhistas correspondem a aproximadamente 65,4\% da remuneração. Parte desse montante, no entanto, não se reflete em retorno monetário para o trabalhador, como, por exemplo, as contribuições ao sistema S (Sesi, Senai, Sebrae) estimados em 3,1\% do salário. Portanto, postula-se, nesta simulação, que $b=0,6 r$, por simplicidade. Estipula-se ainda que a remuneração $r$ corresponda a um salário mínimo, $\mathrm{R} \$ 380$. $^{11} \mathrm{O}$ Instituto Brasileiro de Geografia e Estatística, IBGE, publica regularmente a Pesquisa Mensal de Emprego, ${ }^{12}$ que estima a relação entre o rendimento do trabalhador autônomo em comparação com o trabalhador assalariado. A média dos meses de janeiro de 2003 a dezembro de 2005 estabelece essa relação em 80,2\%, o que nos leva à estimativa da renda do autônomo em $\gamma=$ $\mathrm{R} \$ 300 .^{13}$

Com essas hipóteses, o trabalhador está disposto a esperar a empresa registrá-lo até os seguintes estágios:

Observa-se que, quanto mais a Justiça privilegiar o trabalhador ( $\alpha$ maior), menos ele estará disposto a esperar, ou seja, ele denunciará a empresa mais rapidamente.

11 Valor do salário mínimo referente a abril/2007.

12 Dados disponíveis em http://www.ibge.gov.br/home/estatistica/indicadores/trabalhoerendimento/pme_nova/, acessado em 20/03/2008.

13 O valor exato seria $0,802 \times 380=304,86$, que aproximamos aqui por conveniência para $\mathrm{R} \$ 300$. Observe que, como a renda do autônomo $\gamma$ é menor que $r$, o trabalhador não tem interesse em adiar sua entrada na firma. 
Tabela 2 - Valores de $n(\alpha)$ até os quais o trabalhador não denunciará

\begin{tabular}{c|c}
\hline$\alpha$ & $n(\alpha)$ \\
\hline 0,3 & 166 \\
0,4 & 138 \\
0,5 & 118 \\
0,6 & 103 \\
0,7 & 92 \\
0,8 & 82 \\
0,9 & 74 \\
\hline
\end{tabular}

Cabe neste momento um registro. $\mathrm{O}$ modelo apresentado, por fazer uma análise de equilíbrio parcial, não levou em consideração a demanda de trabalho. No entanto, destaca-se que, se a houvesse incorporado, o aumento do custo poderia reduzir a demanda por trabalho, podendo afetar o efeito do aumento de $\alpha$ sobre o equilíbrio.

\subsection{Equilíbrios de Nash perfeito em subjogo}

A condição (3) estabelece explicitamente um número mínimo de estágios, $n_{\text {min }}(\alpha)$, a partir do qual o empregador terá incentivo a registrar o trabalhador, se estimar que o trabalhador o denunciará caso não seja registrado. Por outro lado, a condição (5) estabelece implicitamente um número máximo de estágios, $n_{\max }(\alpha)$, que um empregado está disposto a esperar para ter sua carteira regularizada. As Tabelas 1 e 2 mostram que, para a parametrização escolhida, temos $n_{\text {min }}(\alpha)<n_{\text {max }}(\alpha)$, para todos os valores de $\alpha$ considerados. Como o empregador não registrará um empregado se não esperar ser denunciado, o único equilíbrio perfeito em subjogos em que há registro é aquele em que $n=n_{\max }(\alpha)=\left\lfloor\frac{1}{\alpha} \frac{1-\delta^{n}}{1-\delta}\right\rfloor$, em que o símbolo $\lfloor x\rfloor$ significa a parte inteira inferior de $x$ que, neste caso, é $x=\frac{1}{\alpha} \frac{1-\delta^{n}}{1-\delta}$. Mais especificamente, o equilíbrio perfeito em subjogos é dado pelo perfil de estratégias a seguir.

Trabalhador: procurar trabalho no período inicial, aceitar trabalhar sem carteira assinada por até $n_{\max }(\alpha)=\left\lfloor\frac{1}{\alpha} \frac{1-\delta^{n}}{1-\delta}\right\rfloor$ períodos. Se sua carteira de trabalho não for assinada até o período $n_{\max }(\alpha)$, denunciar a empresa na Justiça.

Empregador: oferecer trabalho não registrado no período inicial e sempre que o trabalhador procurar emprego. Manter o trabalhador sem registro até o período $n_{\max }(\alpha)=\left\lfloor\frac{1}{\alpha} \frac{1-\delta^{n}}{1-\delta}\right\rfloor$. Registrar sua carteira nesse período $n_{\max }(\alpha)$. 
Os resultados desta seção explicam situações em que a informalidade prevalece durante um determinado tempo e, posteriormente, resulta numa formalização da relação de trabalho. Pode-se interpretar esse período de informalidade como um contrato não registrado de experiência entre trabalhador e empregador que, se for positivo, resulta na formalização do empregado. Destaca-se da análise aqui apresentada um importante papel para as instituições na determinação do equilíbrio, marcada pela dependência de $n_{\max }(\alpha)$ na variável $\alpha$. De fato, quando $\alpha=0,3$, o que corresponde a uma baixa recuperação dos benefícios não recebidos, então o empregado deverá esperar 166 períodos para ter sua carteira assinada. Esse número vai se reduzindo à medida que o parâmetro institucional $\alpha$ aumenta, garantindo uma maior recuperação dos benefícios não recebidos. No caso em que $\alpha=0,9$, chega-se ao mínimo de 74 períodos, inferior à metade do prazo de espera quando $\alpha=0,3$.

A próxima seção discute outro equilíbrio no qual a empresa estará sempre demitindo após um determinado período de tempo, mesmo tendo que arcar com as indenizações determinadas pela Justiça Trabalhista.

\section{EQUILÍBRIO SEM REGISTRO E COM PROCESSO JUDICIAL}

Verifiquemos agora se existe um equilíbrio perfeito em subjogos no qual o empregador contrata o trabalhador, mas não assina sua carteira de trabalho, e o trabalhador, por sua vez, apresenta denúncia na Justiça, desligando-se então da firma e permanecendo autônomo a partir do período seguinte. As estratégias correspondentes são as seguintes: o empregador nunca assina carteira de trabalho do empregado; já o trabalhador solicita emprego no estágio inicial, e trabalha sem carteira assinada até o $n$-ésimo estágio, denunciando nesse estágio a empresa, caso sua situação não seja até então formalizada.

\subsection{Análise para a empresa}

Primeiramente serão analisados os incentivos ao desvio unilateral em um único período do empregador com relação à estratégia acima descrita. Em qualquer estágio em que a firma venha a tomar uma decisão, existe um trabalhador interessado em trabalhar para a firma, independentemente da situação se encontrar dentro ou fora do caminho de equilíbrio.

O único desvio possível do empregador consiste em assinar a carteira do trabalhador em algum período anterior ao período $n$ em que a firma irá denunciá-lo, uma vez que qualquer estratégia envolvendo a contratação após $n$ estágios será inócua. Além disso, dada a estratégia do trabalhador, o melhor desvio possível envolverá a contratação justamente nesse estágio $n$. Uma vez feita a contratação, o empregado se torna estável e não há mais comportamento estratégico. Portanto, o ganho líquido para a firma, desviando do perfil considerado, é dado por:

$$
\Delta \pi=\left[\delta^{n-1} n \alpha e+\delta^{2 n-1} n \alpha e+\cdots\right]-\left[\delta^{n-1} e+\delta^{n} e+\cdots\right]=\frac{\delta^{n-1}}{1-\delta^{n}} n \alpha e-\frac{\delta^{n-1}}{1-\delta} e
$$


Os primeiros termos positivos da expressão acima correspondem à economia que a firma fará ao assinar a carteira do empregado, pois este não entrará na Justiça. Observe que, nesse cômputo, foi considerado que, segundo a estratégia de equilíbrio, a firma é denunciada na Justiça a cada $n$ períodos. Os últimos termos, precedidos do sinal negativo, correspondem ao adicional que a firma passará a pagar a cada período após ter assinado a carteira de trabalho.

A firma não terá interesse em desviar se $\Delta \pi \leq 0$, o que equivale a:

$$
n \leq \frac{1}{\alpha} \frac{1-\delta^{n}}{1-\delta}
$$

Vale observar que a condição acima é oposta à condição (3), que foi encontrada para o equilíbrio com contratação. Ela diz que, se o trabalhador não estiver disposto a esperar tempo suficiente para ser contratado, então é melhor para a firma enfrentar o processo judicial, nunca assinando a carteira do empregado.

\subsection{Análise para o empregado}

Analisemos inicialmente se o trabalhador tem incentivo a não buscar emprego, permanecendo autônomo. Pela propriedade do desvio em um único estágio, basta considerar a situação em que o trabalhador permanece autônomo no estágio inicial, mas busca emprego no estágio seguinte, trabalha $n$ estágios sem carteira, e então denuncia a firma à Justiça. O benefício líquido do desvio é dado por:

$$
\Delta u=\gamma+\delta\left[r+\delta r+\cdots+\delta^{n-1} r+\delta^{n-1} n \alpha b+\delta^{n} \frac{1}{1-\delta} \gamma\right]-\left[r+\delta r+\cdots+\delta^{n-1} r+\delta^{n-1} n \alpha b+\delta^{n} \frac{1}{1-\delta} \gamma\right]
$$

Os primeiros dois termos positivos da expressão anterior correspondem à utilidade quando o trabalhador primeiro mantém-se autônomo por um estágio, buscando emprego em seguida e denunciando a firma na Justiça $n$ estágios após ser contratado. O último termo, precedido do sinal negativo, reflete a utilidade do trabalhador quando ele segue a estratégia de equilíbrio. A expressão pode ser reescrita na forma abaixo.

$$
\Delta u=\gamma-(1-\delta)\left[\frac{1-\delta^{n}}{1-\delta} r+\delta^{n-1} n \alpha b+\delta^{n} \frac{1}{1-\delta} \gamma\right]=\left(1-\delta^{n}\right)(\gamma-r)-(1-\delta) \delta^{n-1} n \alpha b
$$

O trabalhador não terá interesse nesse desvio se $\Delta u \leq 0$, o que equivale à condição abaixo.

$$
n \geq \frac{1}{\delta^{n-1}} \frac{1-\delta^{n}}{1-\delta} \frac{1}{\alpha b}(\gamma-r)
$$

Observe que, se $\gamma \leq r$, então a condição acima estará trivialmente satisfeita. Caso contrário, podemos reescrever a equação (7) como: $\delta^{n-1} n \geq \frac{1-\delta^{n}}{1-\delta} \frac{1}{\alpha b}(\gamma-r)$. É fácil provar que o termo 
à esquerda da desigualdade converge para zero quando $n$ aumenta, enquanto o termo à direita converge para um número real positivo. Portanto, se $\gamma>r$ então é necessário que $n$ não seja muito elevado para que a condição seja satisfeita.

Analisemos agora a situação em que o trabalhador aceita trabalhar para a firma sem carteira assinada. Se o equilíbrio diz que o trabalhador denunciará a firma no estágio $n$, então, para determinar esse estágio, basta analisar para que valores de $n$ a utilidade do trabalhador denunciando a firma no estágio $n$ é maior que a utilidade denunciando no estágio $n+1$. A diferença de utilidade correspondente é:

$$
\Delta u=(r+n \alpha b+\delta \gamma)-(r+\delta r+\delta(n+1) \alpha b)
$$

Os primeiros termos (positivos) na expressão acima correspondem aos ganhos do trabalhador nos estágios $n$ e $n+1$, quando ele denuncia a firma no estágio $n$. Os últimos termos, precedidos do sinal negativo, correspondem aos ganhos nos mesmos estágios quando a denúncia é feita no estágio $n+1$. A expressão acima pode ser reescrita como:

$$
n \geq \frac{\delta}{1-\delta} \frac{r-\gamma+\alpha b}{\alpha b}
$$

Portanto, o único estágio $\bar{n}$ compatível com um equilíbrio perfeito em subjogos é a parte inteira do termo à direita da desigualdade acima.

$$
\bar{n}=\left\lfloor\frac{\delta}{1-\delta} \frac{r-\gamma+\alpha b}{\alpha b}\right\rfloor
$$

Para confirmar que vale a propriedade de desvio em um único estágio, ainda deveríamos considerar desvios em qualquer possível estágio do jogo. No entanto, nossa comparação mostra que não há interesse para o trabalhador em permanecer um tempo superior a $\bar{n}$ no emprego sem carteira assinada. Além disso, se houvesse um período anterior a $\bar{n}$ em que o trabalhador preferisse denunciar a firma, então, como antes do estágio $\bar{n}$ o trabalhador sempre prefere esperar mais um estágio, chega-se imediatamente a uma contradição. Portanto, não é possível ao trabalhador desviar unilateralmente da estratégia de equilíbrio em um único estágio e com isso se beneficiar.

\section{Simulação}

A Tabela 3 apresenta os valores de $\bar{n}(\alpha)$ no equilíbrio sem registro, correspondendo aos respectivos valores de $\alpha$, variando entre 0,3 e 0,9 , para a parametrização descrita anteriormente: $r=\mathrm{R} \$ 380, \gamma=\mathrm{R} \$ 300, b=0,6, \delta=0,98$. Observe que, como $r>\gamma$, a condição (7) é automaticamente satisfeita, ou seja, o trabalhador não tem incentivo a permanecer autônomo desde o primeiro período. 
Tabela 3 - Tempo de espera $\bar{n}(\alpha)$ para que o trabalhador acione a Justiça no equilíbrio sem registro

\begin{tabular}{c|c}
\hline$\alpha$ & $\bar{n}(\alpha)$ \\
\hline 0,3 & 106 \\
0,4 & 91 \\
0,5 & 83 \\
0,6 & 77 \\
0,7 & 73 \\
0,8 & 70 \\
0,9 & 68 \\
\hline
\end{tabular}

\subsection{Equilíbrio de Nash perfeito em subjogo}

A condição (8) determina em que estágio $\bar{n}(\alpha)$ o trabalhador denunciará a firma em um equilíbrio sem registro. Para que se trate de equilíbrio, no entanto, o empregador tem que estar decidido a não registrar o trabalhador nesse estágio, mesmo tendo consciência de que o trabalhador o denunciará na Justiça Trabalhista. Para que isso ocorra, é necessário que esse estágio seja anterior ao estágio $n(\alpha)$ que aparece na Tabela 1. A comparação entre as Tabelas 1 e 3 mostra claramente o papel das instituições na existência desse equilíbrio. De fato, se as instituições trabalhistas são muito fracas, o que corresponde a valores de $\alpha$ iguais a 0,3 e 0,4 , existe equilíbrio sem registro, que envolve elevado tempo de espera até o trabalhador denunciar a firma na Justiça. Vale recordar que as estimativas para o Brasil nos colocam, infelizmente, na categoria de países ${ }^{14}$ de baixos valores de $\alpha$.

Por outro lado, se a Justiça for mais eficiente, o que corresponde a valores de $\alpha$ de pelo menos 0,5 , então o empregador preferirá registrar o trabalhador antes que ele o denuncie na Justiça, de forma que não existe equilíbrio sem registro. Esta constatação sugere que uma elevação do valor atualmente estimado no Brasil de 0,4 para 0,5 poderia significar um grande passo na direção, senão da eliminação total do período sem registro, pelo menos da eliminação do equilíbrio em que a carteira nunca é registrada.

Quando o equilíbrio sem registro existe, ele tem a seguinte forma: o trabalhador busca emprego no estágio inicial do jogo, trabalha sem carteira assinada por $\bar{n}$ estágios, e então denuncia a firma na Justiça, recebendo a parcela $\bar{n} \alpha b$ dos benefícios devidos, e tornando-se autônomo a partir de então. O empregador, por sua vez, contrata novos empregados, mas os mantêm sempre na informalidade, substituindo um empregado por outro informal quando este o denuncia na Justiça. 


\section{CONCLUSÃo}

Este estudo focou a informalidade no mercado de trabalho sob a ótica da Teoria dos Jogos, evidenciando o comportamento dos agentes envolvidos e de como o funcionamento da Justiça Trabalhista pode afetar a formalização dos contratos. Procurou-se ressaltar que as mudanças institucionais, a exemplo das condições macroeconômicas, têm importantes impactos sobre o tipo de postos de trabalho gerados.

Mostra-se primeiramente que existe um equilíbrio em que o empregado é contratado informalmente e, após determinado período, ele tem sua carteira de trabalho assinada. Esse resultado confirma Perry et al. (2007), em que se afirma que a informalidade pode acontecer simplesmente porque os agentes estão maximizando suas respectivas utilidades.

Assim como Camargo (1996), que focou os incentivos no mercado de trabalho, associados ao conjunto das instituições, a solução do modelo vislumbrado neste estudo permite concluir que, quanto mais eficiente o quadro institucional, ou seja, quanto mais a Justiça Trabalhista obriga os empregadores a pagarem a integralidade dos benefícios a que os empregados teriam direito, mais rapidamente acontecerá a formalização do contrato de trabalho nesse equilíbrio em que o empregador formaliza o trabalho após um período inicial sem carteira assinada.

O modelo confirma também o que parece ser a realidade em certos mercados de trabalho em que, sob certas condições, o empregador prefere manter os empregados na informalidade, mesmo sabendo que isso acarretará despesas trabalhistas na Justiça. Ou seja, as firmas adotam a sistemática de contratar informalmente e demitir freqüentemente, contribuindo para a alta rotatividade da mão-de-obra. Essa inferência está de acordo com a grande rotatividade agregada do mercado de trabalho brasileiro, principalmente no setor terciário, como descreve Corseuil et al. (2002). Constata-se, assim, uma triste convergência do mercado de trabalho para uma situação de estabilidade da informalidade em níveis elevados. Apesar do resultado negativo, o presente estudo também evidencia que o equilíbrio sem registro não existe se a Justiça consegue garantir ao trabalhador elevado porcentual de recuperação dos benefícios não pagos pela firma durante o período de informalidade. Nesse caso, a firma prefere assinar a carteira do trabalhador antes que ele a denuncie na Justiça.

Esses resultados sugerem, para o combate da informalidade, a tomada de políticas públicas como reformar a Justiça Trabalhista, tornando-a mais ágil, com julgamentos que reflitam os reais direitos dos trabalhadores, ou, talvez, criar outras instâncias de conciliação entre empregados e empregadores não vinculadas ao Poder Judiciário, que garantam celeridade e justiça às disputas trabalhistas. Segundo o presente estudo, essa reforma tem dois importantes efeitos. Em primeiro lugar, faz com que as firmas assinem a carteira de trabalho mais rapidamente, no caso do equilíbrio com registro adiado, reduzindo o tempo de informalidade na economia. Em segundo lugar, pode acabar com o nefasto equilíbrio em que a firma nunca assina a carteira do trabalhador, substituindo-o por outro informal quando este a aciona na Justiça. 
Os resultados encontrados neste artigo reforçam a literatura existente com o instrumental do comportamento estratégico. No entanto, ainda são oriundos de um modelo com hipóteses restritivas, como a simultaneidade para o empregado entre recorrer à Justiça e a perda do emprego, bem como o fato de o trabalhador tornar-se irreversivelmente autônomo após a denúncia. Além disso, nossas simulações são todas baseadas na hipótese de que $r>\gamma$ e o valor de $b$, ainda que baseado em estudos existentes, não discrimina os benefícios recebidos pelo trabalhador no momento da demissão, como o depósito na conta vinculada do trabalhador no FGTS, de importância igual a $40 \%$ do montante acumulado durante a vigência do contrato de trabalho (hipótese de despedida sem justa causa), ou o seguro-desemprego a que o demitido tem direito. Adicionalmente, no presente modelo, a única diferença salarial entre o empregado com carteira assinada e aquele sem carteira é o benefício $b$, não havendo adicional de salário ao empregado sem carteira. Deixa-se como sugestão para pesquisas futuras desenvolver novas versões do jogo relaxando essas hipóteses, de forma a tornar o modelo mais próximo da realidade.

\section{REFERÊNCIAS}

ACEMOGLU, D. Good jobs versus bad jobs. Journal of Labor Economics, v. 19, n. 1, 2001.

BANCO MUNDIAL; IPEA. Relatório: empregos no Brasil, v. 1, 2002. (Seção Informativa sobre Política).

CACCIAMALI, M. As economias informal e submersa: conceitos e distribuição de renda. In: CAMACHO, J. M.; GIAMBIAGI, F. (Org.). Distribuição de renda no Brasil. São Paulo: Paz e Terra, 1991.

CAMARGO, J. M. Flexibilidade e produtividade do mercado de trabalho brasileiro. In . (Org.). Flexibilidade do mercado de trabalho no Brasil. Rio de Janeiro: Editora Fundação Getúlio Vargas. 1996.

CARDOSO JR., J. C.; FERNANDES, S. A informalidade revisitada: evolução nos últimos 20 anos e mais uma hipótese para pesquisa. Mercado de Trabalho - Conjuntura e Análise, IPEA/MTE, n. 14, out. 2000 .

CORSEUIL, C. H.; RIBEIRO, E. P.; SANTOS, D. D.; DIAS, R. Criação, destruição e realocação do emprego no Brasil. IPEA, 2002. (Texto para Discussão, n. 855).

EHRENBERG, R. G.; SMITH, R. S. A moderna economia do trabalho: teoria e política pública. 5. ed. Makron Books, 2000.

FERNANDES, F.; ROLLI, C. Justiça do Trabalho só atende desempregado. Jornal Folha de São Paulo, 5 maio 2003.

FUDENBERG, D.; TIROLE, J. Game theory. 3. ed. Cambridge: The MIT Press, 1991.

IPEA; MTE. Mercado de Trabalho - Conjuntura e Análise, v. 24, Brasília: IPEA/MTE, 2004.

MADALOZZO, R. C. ; MARTINS, S. R. . Gender wage gaps: comparing the 80s, 90s, and 00 in Brazil. In: 7TH GLOBAL CONFERENCE ON BUSINESS \& ECONOMICS, Roma, 2007.

MENEZES-FILHO, N. A.; MENDES, M.; ALMEIDA, E. S. O diferencial de salários formal-informal: segmentação ou viés de seleção? Revista Brasileira de Economia, v. 58, n. 2., 2004.

MINISTÉRIO DA PREVIDÊNCIA SOCIAL. Conjuntura social. Brasília: Ministério da Previdência Social, v. 14, n. 1, maio-ago. 2003 
NERI, M. Empregos e negócios informais: subsídios para políticas. Mercado de trabalho - conjuntura e análise, IPEA/MTE, out. 2000.

NERI, M. Diretos trabalhistas, encargos e informalidade. Conjuntura Econômica, p. 38-41, set. 2000 . Cobertura previdenciária: diagnóstico e propostas. Conjuntura Social. Ministério da Previdência Social, maio-ago 2003.

PERRY, G. E.; MALONEY, W. F.; ARIAS, O. S.; FAJNZYLBER, P.; MASON, A. D.; SAAVEDRACHANDUVI, J. Informality - exit and exclusion. World Bank, 2007.

RAMOS, L.; BRITTO, M. O funcionamento do mercado de trabalho metropolitano brasileiro no período 1991-2002: tendências, fatos estilizados e mudanças estruturais. IPEA, 2004. (Texto para Discussão, n. 1011).

RAMOS, L.; FERREIRA, V. Padrões espacial e setorial da evolução da informalidade no Brasil-1991-2003. IPEA, 2005. (Texto para Discussão, n. 1099).

RAMOS, L. O desempenho recente do mercado de trabalho brasileiro: tendências, fatos estilizados e padrões espaciais. IPEA, 2007. (Texto para Discussão, n. 1255).

RAUCH, J. E. Modelling the informal sector formally. Journal of Development Economics, v. 35, p. 33-47, 1991.

RIBEIRO, R. N.; BUGARIN, M. N. S. Fatores determinantes e evolução da economia submersa no Brasil. Estudos Econômicos, v. 33, n. 3, p. 435-466, 2003.

SOARES, F. V. Some stylized facts of the informal sector in Brazil in the 1980's and 1990's. IPEA. 2004a. (Texto para Discussão, n. 1020). n. 1021).

. Do informal workers queue for formal jobs in Brazil? IPEA, 2004b. (Texto para Discussão,

TRIBUNAL SUPERIOR DO TRABAHO. Relatório geral da Justiça do Trabalho. 2006.

ULYSSEA, G. Informalidade no mercado de trabalho brasileiro: uma resenha da literatura. IPEA, 2005a. (Texto para Discussão, n. 1070). n. 1096).

. Instituições e a informalidade no mercado de trabalho. IPEA, 2005b. (Texto para Discussão, 